\title{
Absent or reversed end diastolic flow velocity in the umbilical artery and necrotising enterocolitis
}

\author{
G Malcolm, D Ellwood, K Devonald, R Beilby, D Henderson-Smart
}

\begin{abstract}
Absent or reversed end diastolic flow (AREDF) velocities in the umbilical artery were identified in $\mathbf{2 5}$ high risk pregnancies. In six pregnancies the fetus was abnormal and all but one of these ended in perinatal death. Of the 19 morphologically normal fetuses, three died in utero and there were four neonatal or infant deaths. The mortality rate was $\mathbf{4 8 \%}$ for all pregnancies and $37 \%$ for those with morphologically normal fetuses. There was a highly significant increased risk for the development of necrotising enterocolitis in those morphologically normal fetuses with AREDF (53\%) compared with controls (6\%) who did have umbilical artery end diastolic flow velocities in fetal life. There were no significant differences between the matched pairs for parameters of neonatal outcome chosen to reflect neonatal morbidity. These findings demonstrate the close association between AREDF and necrotising enterocolitis that appears to be independent of other variables such as degree of growth retardation, prematurity, and perinatal asphyxia.
\end{abstract}

Doppler ultrasound technology has made it possible to study the flow characteristics of the fetal circulation. ${ }^{1}$ Over the past decade many data have been reported which link abnormal umbilical artery flow velocity waveforms with growth retardation and perinatal asphyxia. ${ }^{2}{ }^{3}$ However, the exact role for such measurements in the management of high risk pregnancy remains unclear. ${ }^{4}$ Recent reports have suggested an association between very abnormal umbilical artery and fetal aorta Doppler studies showing absent or reversed end diastolic flow (AREDF) velocities and severe neonatal morbidity including necrotising enterocolitis. ${ }^{56}$ This may simply reflect the fact that very growth retarded, preterm fetuses are more likely to demonstrate AREDF and will often develop necrotising enterocolitis. This paired analysis study was designed to test the hypothesis that it is AREDF, independent of growth retardation and prematurity, which predisposes to necrotising enterocolitis.

\section{Methods}

Over a three year period (April 1987 to April 1990 ) over 1000 high risk pregnancies were monitored by the recording of flow velocity waveforms from the umbilical artery. All fetuses were studied using a GE RT3600 ultrasound system with pulsed Doppler. Waveforms were obtained using a $5 \mathrm{MHz}$ phased array sector transducer, and a $100 \mathrm{~Hz}$ wall filter was used. In each study waveforms were continuously displayed until an optimum signal was obtained and then five consecutive waveforms selected for analysis. Waveforms were analysed for both maximum systolic:minimum diastolic ratio (A:B ratio) and pulsatility index. ${ }^{7}$ The results of Doppler studies were not revealed to obstetricians or neonatologists involved in the management of these pregnancies. The study was approved by the hospital ethics committee and all patients gave informed consent.

From these pregnancies 25 cases were identified in which there was AREDF in the umbilical artery. Liveborn fetuses without congenital malformations were subjected to analysis of parameters of neonatal outcome. One neonate who survived two hours only was excluded from further analysis. These neonates were matched for gestational age and birth weight with neonates in whom Doppler studies had consistently shown end diastolic flow in the umbilical artery before delivery. Controls were drawn from the nursery population during the same time period as the cases and were chosen for best fit for both birth weight and gestational age.

For the matched pairs the following were analysed as dichotomous variables:

(1) Respiratory distress defined as over six hours supplemental oxygen or respiratory support.

(2) Perinatal asphyxia defined as any one of these criteria: cord arterial $\mathrm{pH}<7 \cdot 15$, base deficit $>9 \mathrm{mmol} / \mathrm{l}$, Apgar score $<4$ at one minute or 7 at five minutes.

(3) Neutropenia ( $<2 \times 10^{9} / 1$ neutrophils) and/ or thrombocytopenia $\left(<100 \times 10^{9} / 1\right.$ platelets $)$ on initial blood count.

Necrotising enterocolitis was classified as none, suspect, or proved. The suspect group had the clinical features of necrotising enterocolitis (that is, abdominal distension, bile aspirates or vomiting, blood in the stools, and systemic illness) and were treated with parenteral nutrition and antibiotics. Proved cases had in addition the radiological features of pneumatosis coli, perforation, or gas in the portal circulation. Laparotomy or necropsy evidence was also classified as proved necrotising enterocolitis.

Neonatal radiographs and ultrasound scans were reviewed by a paediatric radiologist without knowledge of the clinical history. All the neonates less than 32 weeks' gestation, all ventilated neonates, and all those with abnormal neurological signs received routine cranial ultrasound examinations in this nursery. The num- 
ber of days of positive pressure ventilation and maximum supplemental oxygen concentration were analysed as continuous, non-parametric variables. Birth weights, all being below the 20th centile, were treated as continuous, nonparametric variables. Birth weight and head circumference at birth were standardised to the normal population before analysis. ${ }^{8}$ Statistical methods used were the Wilcoxon rank sum test for continuous variables, McNemar's test for paired dichotomous outcome variables, and Fisher's exact test for unpaired dichotomous outcome variables. For the necrotising enterocolitis data proved and suspected cases were combined and the data analysed as matched pairs by McNemar's test.

\section{Results}

During this period 25 pregnancies were identified in which fetuses showed AREDF. The pregnancies were complicated by hypertension $(\mathbf{n}=$ 11), obstetric lupus syndrome $(n=3)$, unexplained growth retardation $(n=3)$, renal failure $(n=1)$, twins $(n=1)$, and congenital malformations $(n=6)$. Those with congenital malformations have been excluded from further analysis. Of the 19 morphologically normal fetuses three died in utero and one died within 24 hours of birth, leaving 15 neonates (the cases) to be matched with controls. The overall mortality in fetuses with AREDF was $48 \%$ (12/25). Excluding congenital malformations the mortality was $37 \%$ (7/19). The three neonates from the case group of 15 who died did so at 42,180 , and 190 days respectively. The causes of death were complications of fulminating necrotising enterocolitis in the first of these and chronic lung disease in the second and third. There were no deaths in the control group.

MATCHED PAIRS

The gestational age at delivery ranged from 26-
35 weeks (mean (SD) $30.5(2.95)$ weeks) for the cases and 26-34 weeks (mean (SD) 30.4 (2.85) weeks) for the control group. The birth weight ranged from 504-1635 $\mathrm{g}$ (mean (SD) 1059 (343) $\mathrm{g}$ ) in the cases and 515-1748 $\mathrm{g}$ (mean (SD) 1079 (353) $\mathrm{g}$ in the control group. There were no significant differences between the cases and controls for birth weight $(p=0.85)$ or gestational age $(p=0.82)$ by Wilcoxon rank sum test. There were eight boys and seven girls in the cases and four boys and 11 girls in the control group.

The characteristics of the matched pairs are shown in table 1 . Table 2 shows the incidence of proved or suspect necrotising enterocolitis in the two groups. There is a highly significant increase in the incidence of necrotising enterocolitis in neonates who demonstrated AREDF $\left(\chi^{2}=5 \cdot 14\right.$, df $1,0.05>p>0.01$ by McNemar's test).

When matched pairs were examined for the presence of asphyxia there were five discordant pairs but in four of these the direction was towards the control. Similarly for respiratory distress there were six discordant pairs with the direction being towards the control in five.

Table 2 Incidence of necrotising enterocolitis

\begin{tabular}{lllc}
\hline & Proved & Suspect & None \\
\hline Cases & 5 & 3 & 7 \\
Controls & 1 & 0 & 14
\end{tabular}

Table 3 Morbidity assessed by days of positive pressure ventilation and maximum supplemental oxygen

\begin{tabular}{lcllll}
\hline & \multicolumn{2}{c}{ Day of ventilation } & \multicolumn{2}{l}{$\begin{array}{l}\text { Maximum oxygen } \\
\text { concentration (\%) }\end{array}$} \\
\cline { 2 - 3 } \cline { 5 - 6 } & Mean (SD) & Range & & Mean (SD) & Range \\
\hline Cases & $14(30)$ & $0-100$ & & $41(24)$ & $21-100$ \\
Controls & $9(13)$ & $0-40$ & $54(32)$ & $21-100$
\end{tabular}

There were no significant differences between the matched pairs for days of ventilation $(p=0.62)$ and maximum oxygen concentration $(p=0 \cdot 27)$ by the Wilcoxon rank sum test.

Table 1 Details of case-control pairs

\begin{tabular}{|c|c|c|c|c|c|c|c|c|c|}
\hline \multicolumn{2}{|c|}{ Pair } & \multirow{2}{*}{$\begin{array}{l}\text { Sex } \\
\mathrm{F}\end{array}$} & \multirow{2}{*}{$\begin{array}{l}\begin{array}{l}\text { Birth } \\
\text { weight } \\
\text { (g) }\end{array} \\
670\end{array}$} & \multirow{2}{*}{$\begin{array}{l}\begin{array}{l}\text { Gestational } \\
\text { age } \\
\text { (weeks) }\end{array} \\
28\end{array}$} & \multirow{2}{*}{$\begin{array}{l}\begin{array}{l}\text { Head } \\
\text { circumference } \\
(\mathrm{cm})\end{array} \\
23 \cdot 8\end{array}$} & \multirow{2}{*}{$\begin{array}{l}\text { Asphyxia } \\
\text { Yes }\end{array}$} & \multirow{2}{*}{$\begin{array}{l}\text { Respiratory } \\
\text { distress }\end{array}$} & \multirow{2}{*}{$\begin{array}{l}\text { Necrotising } \\
\text { enterocolitis }\end{array}$} & \multirow{2}{*}{$\begin{array}{l}\text { Neutropenia/ } \\
\text { thrombocytopenia }\end{array}$} \\
\hline 1 & Case & & & & & & & & \\
\hline & Control & $\mathrm{F}$ & 680 & 28 & $23 \cdot 5$ & Yes & Yes & None & Yes \\
\hline 2 & Case & $\mathrm{F}$ & 1635 & 35 & $30 \cdot 2$ & No & No & Proved & Yes \\
\hline & Control & $\mathrm{F}$ & 1748 & 34 & $30 \cdot 5$ & No & No & None & No \\
\hline 3 & Case & $\mathbf{M}$ & 800 & 28 & $25 \cdot 0$ & No & Yes & Proved & Yes \\
\hline & Control & $\mathbf{F}$ & 846 & 28 & $25 \cdot 0$ & Yes & Yes & None & Yes \\
\hline 4 & Case & $\mathbf{M}$ & 1305 & 34 & $28 \cdot 0$ & No & No & None & Yes \\
\hline & Control & $\mathrm{F}$ & 1235 & 33 & $28 \cdot 5$ & No & No & None & No \\
\hline 5 & Case & $\mathrm{F}$ & 1400 & 33 & $28 \cdot 5$ & No & No & None & Yes \\
\hline & Control & $\mathbf{F}$ & 1540 & 33 & $28 \cdot 7$ & No & Yes & None & No \\
\hline 6 & Case & $\mathbf{M}$ & 920 & 28 & $25 \cdot 0$ & No & Yes & None & No \\
\hline & Control & $F$ & 860 & 28 & $25 \cdot 0$ & No & Yes & None & No \\
\hline 7 & Case & $\mathrm{F}$ & 540 & 27 & $20 \cdot 9$ & No & Yes & Suspected & Yes \\
\hline & Control & M & 515 & 27 & $22 \cdot 5$ & Yes & Yes & None & Yes \\
\hline 8 & Case & M & 967 & 31 & $27 \cdot 4$ & No & No & Suspected & No \\
\hline & Control & $\mathbf{F}$ & 1055 & 32 & $26 \cdot 0$ & No & No & Proved & No \\
\hline 9 & Case & M & 1100 & 30 & $27 \cdot 5$ & No & No & None & Yes \\
\hline & Control & M & 1175 & 30 & $27 \cdot 7$ & Yes & Yes & None & Yes \\
\hline 10 & Case & M & 623 & 26 & $23 \cdot 0$ & Yes & Yes & None & No \\
\hline & Control & $\mathrm{F}$ & 654 & 26 & $25 \cdot 0$ & Yes & Yes & None & No \\
\hline 11 & Case & M & 1047 & 29 & $27 \cdot 1$ & No & No & Proved & No \\
\hline & Control & $\mathrm{F}$ & 1114 & 29 & $26 \cdot 1$ & Yes & Yes & None & No \\
\hline 12 & Case & $\mathbf{F}$ & 875 & 29 & $25 \cdot 5$ & Yes & No & Proved & Yes \\
\hline & Control & $\mathbf{M}$ & 910 & 28 & $25 \cdot 0$ & Yes & Yes & None & Yes \\
\hline 13 & Case & $\mathbf{F}$ & 1500 & 34 & $29 \cdot 5$ & No & No & None & Yes \\
\hline & Control & M & 1375 & 34 & $31 \cdot 2$ & No & No & None & No \\
\hline 14 & Case & M & 1470 & 34 & $31 \cdot 0$ & No & No & None & No \\
\hline & Control & $\mathrm{F}$ & 1480 & 34 & $28 \cdot 5$ & No & No & None & No \\
\hline 15 & Case & $\mathrm{F}$ & 1069 & 32 & $26 \cdot 1$ & Yes & Yes & Proved & Yes \\
\hline & Control & $\mathrm{F}$ & 995 & 32 & $27 \cdot 5$ & No & No & None & No \\
\hline
\end{tabular}


However, for haematological abnormalities the five discordant pairs were all in the direction of the cases. This just fails to reach significance at $\mathrm{p}=\mathbf{0} .07$ (McNemar's test). There were no significant differences between the matched pairs for neonatal morbidity assessed by days of positive pressure ventilation or maximum supplemental oxygen concentration (table 3 ). There were two cases of periventricular haemorrhage (one grade 3 and one grade 4), both in the index group.

\section{Discussion}

These data clearly demonstrate the poor outcome in pregnancies in which umbilical artery blood flow shows AREDF, with a corrected mortality rate of $37 \%$ in this series. This figure is the same as that arrived at by Pearce in a meta-analysis of a number of studies of similar pregnancies. ${ }^{6}$ Moreover, the poor neonatal outcome suspected from these uncontrolled series is confirmed by a paired analysis which shows the highly significant increased risk for liveborn fetuses of developing necrotising enterocolitis. By analysing other parameters of neonatal outcome that may predipose to necrotising enterocolitis, such as standardised birth weight, gestational age, asphyxia, and need for ventilator support it appears that this increased risk of necrotising enterocolitis may be independent of these other variables. Larger numbers of patients may have revealed a significant association between necrotising enterocolitis and haematological abnormalities such as neutropenia and thrombocytopenia.

The conclusion can be drawn that it is not just the smallest and sickest neonates who show AREDF and then go on to develop necrotising enterocolitis. Therefore, it may be inferred that the presence of AREDF must have some significance for the aetiology of necrotising enterocolitis. Although there is no unifying concept of the aetiology of necrotising enterocolitis, underperfusion and/or hypoxia of the gut are thought to be among the more important aetiological factors. ${ }^{9}$ An association between fetal compromise and redistribution of fetal blood flow has been demonstrated by analysis of internal carotid and umbilical artery Doppler studies. ${ }^{10}$ It has been proposed that blood flow redistribution to the head, myocardium, and adrenals may explain the 'brain sparing' effect seen in some growth retarded neonates. ${ }^{11}$ This redistribution may predispose the neonate to necrotising enterocolitis by sacrificing flow in the descending aorta and consequently in the splan- chnic circulation. The mechanism of "head sparing' may therefore predispose the fetus to necrotising enterocolitis. Analysis of the ratio of standardised head circumference to standardised birth weight does not, however, show a difference either between the two groups or within the index group between those with and without necrotising enterocolitis. This may be explained by the early onset of growth retardation in many of these cases. Further study of blood flow redistribution using Doppler is warranted. The demonstration of AREDF places the fetus at high risk of perinatal or infant death. The neonate is also at considerable risk of developing necrotising enterocolitis. Neonatologists should be alerted to this finding to facilitate preventative treatment or early detection of necrotising enterocolitis.

AREDF could also be used in case finding for prospective, controlled trials of necrotising enterocolitis prevention or treatment. Obstetricians should also be aware of the high incidence of fetal abnormality in the growth retarded fetus with AREDF.

We would like to thank $\operatorname{Dr} \mathrm{J}$ Anderson and Dr A Boogert for allowing us to study their patients. We also thank Ms Deborah Edwards for statistical advice.

1 FitzGerald DE, Drumm JE. Non-invasive measurement of human fetal circulation using ultrasound: a new method. human fetal circulation

2 Trudinger BJ, Cook CM, Jones L, Giles WB. A comparison of fetal heart-rate monitoring and umbilical artery waveforms in the recognition of fetal compromise. $\mathrm{Br} \mathcal{F}$ Obstet Gynaecol 1986;93:171-5.

3 Fleischer A, Schulman H, Farmakides G, Bracero L, Blattner P, Randolph G. Umbilical artery velocity waveforms and intrauterine growth retardation. Am $\mathcal{J}$ Obstet Gynecol 1985;151:502-5.

4 Trudinger BJ, Cook CM, Giles WB, Connelly A, Thompson RS. Umbilical artery flow velocity waveforms in high-risk pregnancy. Randomised controlled trial. Lancet 1987;i: 188-90.

5 Hackett GA, Campbell S, Gamsu H, Cohen-Overbeek T, Pearce JMF. Doppler studies in the growth retarded fetus and prediction of neonatal necrotising enterocolitis, hae-

morrhage and neonatal morbidity. BMF 1987;294:13-6. Pearce JM. Doppler ultrasound blood velocity waveforms. In: Spencer JAD, ed. Fetal monitoring; physiology and techniques of antenatal and intrapartum

7 Gosling RG, King DH. Ultrasonic angiology. In: Hascus AW, Adamson L, eds. Arteries and veins. Edinburgh: AW, Adamson L, eds. Arteries and
Churchill Livingstone, 1975:61-98.

8 Kitchen WH, Robinson HP, Dickson AJ. Revised intrauterine growth curves for an Australian hospital population. Aust Paediatr $\mathcal{f}$ 1983;19:157-61.

9 Pearse RG, Roberton NRC. In: Roberton NRC, ed. Textbook of neonatalogy. Edinburgh: Churchill Livingstone, 1986: $752-5$

10 Wladimiroff JW, Noordam MJ, Van den Wijngaard JAGW, Hop WCJ. Fetal internal carotid and umbilical artery waveforms as a measure of fetal well-being in intrauterine growth retardation. Pediatr Res 1988;24:609-12.

11 Campbell S, Thoms A. Ultrasound measurement of the fetal head to abdomen circumference ratio in the assessment of growth retardation. Br 7 Obstet Gynaecol 1977;84:165-74. 